\title{
Aortic reconstruction for an infected stent graft with a composite homograft
}

\author{
Jonathan M. Philpott, MD, ${ }^{\mathrm{a}}$ and Christian W. Zemlin, PhD, ${ }^{\mathrm{b}, \mathrm{c}}$ Norfolk, Va
}

\footnotetext{
From the ${ }^{\mathrm{a} S e n t a r a}$ Heart Hospital; the ${ }^{\mathrm{b}}$ Department of Electrical and Computer Engineering, Old Dominion University; and the ${ }^{c}$ Frank Reidy Center for Bioelectrics, Old Dominion University, Norfolk, Va Disclosures: Authors have nothing to disclose with regard to commercial support.

Received for publication May 4, 2016; revisions received Aug 10, 2016; accepted for publication Sept 5, 2016; available ahead of print Oct 4, 2016

Address for reprints: Jonathan M. Philpott, MD, 600 Gresham Dr, Suite 8600, Norfolk, VA 23507-1904 (E-mail: jmphilpott@me.com).

J Thorac Cardiovasc Surg 2017;153:e73-5

$0022-5223 / \$ 36.00$

Copyright (c) 2016 by The American Association for Thoracic Surgery

http://dx.doi.org/10.1016/j.jtcvs.2016.09.011
}

The repair of infected aortic grafts, thoracic endovascular aneurysm repairs, and inflammatory aneurysms remain a formidable challenge. ${ }^{1-5}$ Resection of foreign-body material (grafts) and reconstruction using homografts remain the criterion standard, but they are difficult to carry out when the aortic arch and descending thoracic aorta are involved.

\section{CLINICAL SUMMARY}

A 56-year-old man was seen with a 9.6-cm rapidly enlarging pseudoaneurysm (31\% in the 2 weeks before surgery) of the aortic arch above. The pseudoaneurysm involved a thoracic endovascular aneurysm repair graft that had been placed in the descending aorta for a dilatation of an aneurysm 7 years earlier and was infected with methicillin-sensitive Staphylococcus aureus. There was significant compression of the trachea, esophagus, and left main stem bronchus (Figure 1), and the patient had left subclavian steal syndrome. After admission to the emergency department, brain magnetic resonance imaging showed multifocal lesions that suggested an acute infarct with a probable embolic source. On examination, the patient was confused, restless, and manifested difficulty speaking. On the morning of surgery, the patient was in shock with acute renal failure and had an acute stroke after septic embolism, but he was following commands and moving all 4 extremities, so surgery was performed in an attempt to save his life.

In the operating room, the right subclavian artery (SCA) and right femoral artery were exposed, 8-mm grafts were sewn end-to-side for arterial inflow during cardiopulmonary bypass, and a median sternotomy was performed. The anatomy superior to the heart was unrecognizable from the intense inflammation around the aortic pseudoaneurysm. Bypass was initiated with cooling to $15^{\circ} \mathrm{C}$, and the heart was arrested and herniated into the right side of the chest through an opening in the right pericardium. Through

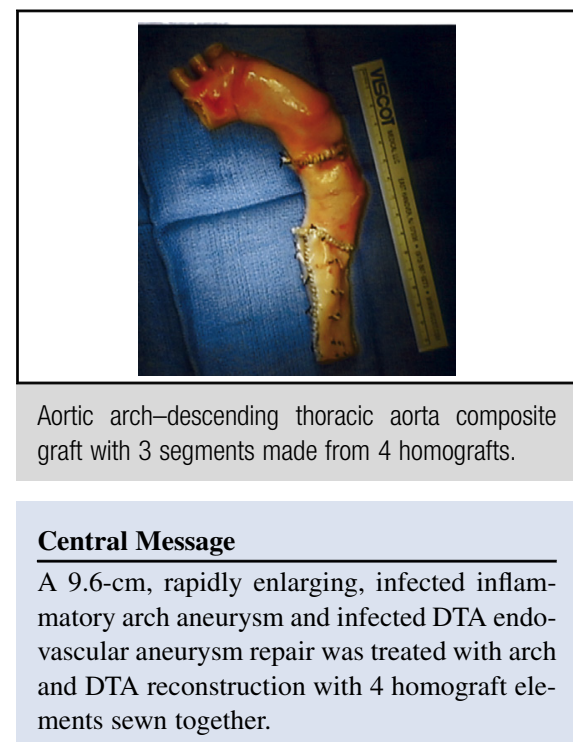

See Editorial Commentary page e77.

this opening and a small left anterior thoracotomy, the DTA was exposed about 1 inch above the diaphragm through the posterior pericardium. After we inspected the dilated aneurysm and determined how far the graft needed to extend, we decided to sew individual homograft elements together to create the new homograft arch-DTA graft shown in Figure 2. Four aortic homograft elements were used: A reversed root-arch element, an ascending aorta element, and 2 adolescent DTAs cut longitudinally and then sewn together. Reversing the first root-arch element allowed the composite graft to mimic the natural shape of the arch.

At $15^{\circ} \mathrm{C}$ deep hypothermic circulatory arrest was initiated. The pseudoaneurysm was opened to determine the location of the great vessels from the inside of the aorta. The openings of the innominate artery (IA) and left common carotid artery (CCA) were visualized, but the left SCA orifice was obliterated. The thoracic endovascular aneurysm repair graft was free floating and was removed. The inflammatory tissue around the arch and the great vessels was quickly débrided, and the now visible IA was clamped and flow through the right SCA resumed to begin antegrade cerebral perfusion. Flow to the left CCA was established with direct cannulation with a $20 \mathrm{~F}$ arterial cannula. The DTA was occluded with 


\section{Before}
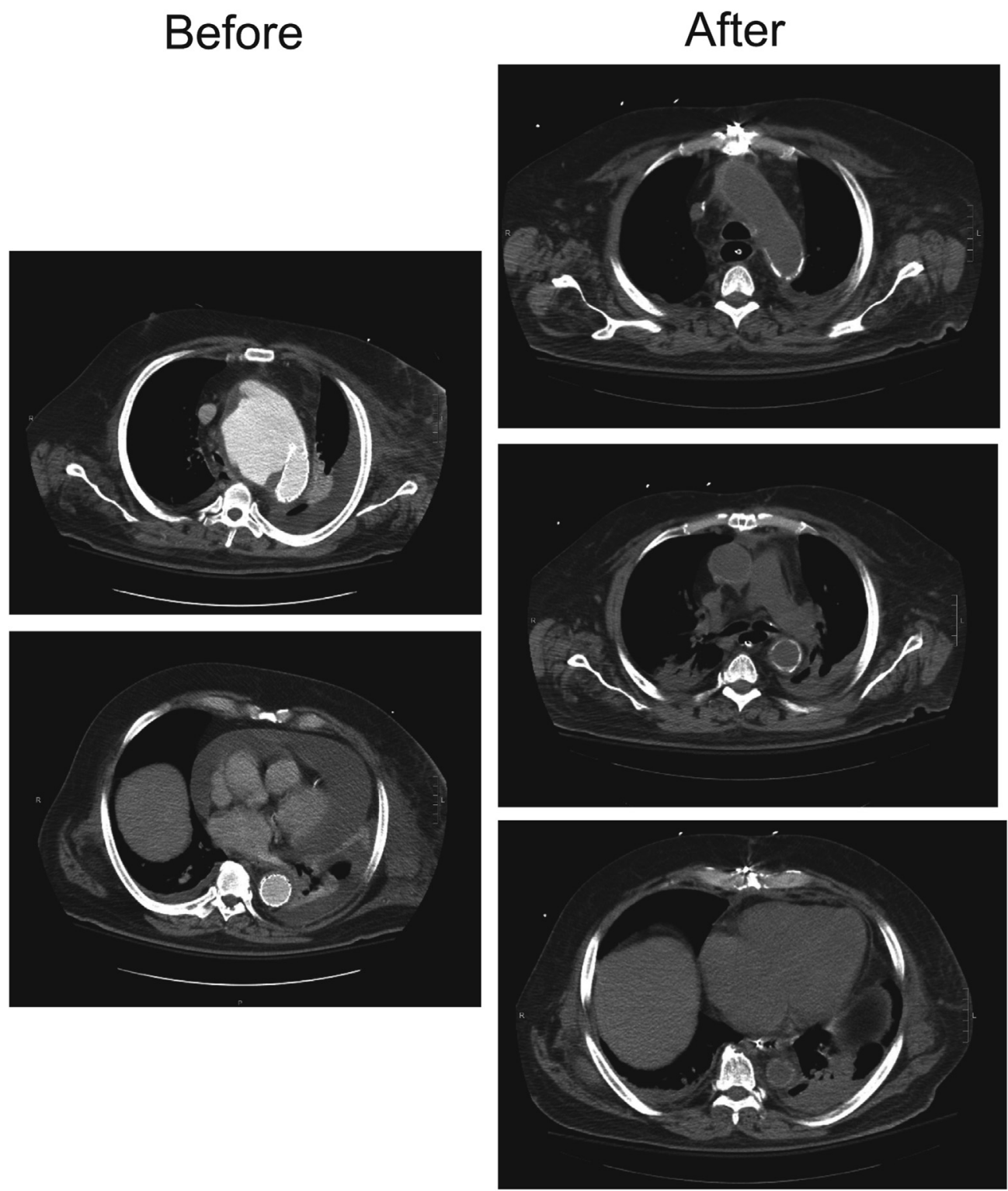

FIGURE 1. Chest compression is relieved by procedure in coronal computed tomographic sections. Before the procedure, the trachea, esophagus, and left main stem bronchus were all severely compressed (left panels). After the procedure, compression was relieved (right panels).

a balloon catheter and flow through the left femoral artery resumed to provide lower body perfusion. The distal DTA just above the diaphragm was opened transversely but not divided along the back wall, and a chest tube was passed through the arteriotomy to the open arch and used to tunnel the composite homograft into position. The distal anastomosis was performed beginning at the posterior wall to affix the homograft into position to the native aorta. The IA on the reversed homograft was then sewn to the left CCA. The homograft left SCA and left CCA were now sewn together to make a single large branch and sewn to the patient's IA with nearly perfect size matching. The proximal aortic anastomosis was completed, and the crossclamp was removed. On rewarming, we easily separated the patient from bypass and secured hemostasis, and the patient was packed open. The total cardiopulmonary bypass time was 450 minutes, and the total crossclamp time was 262 minutes.

The patient was successfully resuscitated in the intensive care unit and closed uneventfully 48 hours later. He underwent a prolonged but complete recovery. He is neurologically intact, and the reconstructed aorta was durable at 2 years.

\section{DISCUSSION}

In conclusion, tissue reconstruction of the arch and DTA is technically feasible with multiple homograft segments; availability of a variety of grafts is very helpful. Reversing 


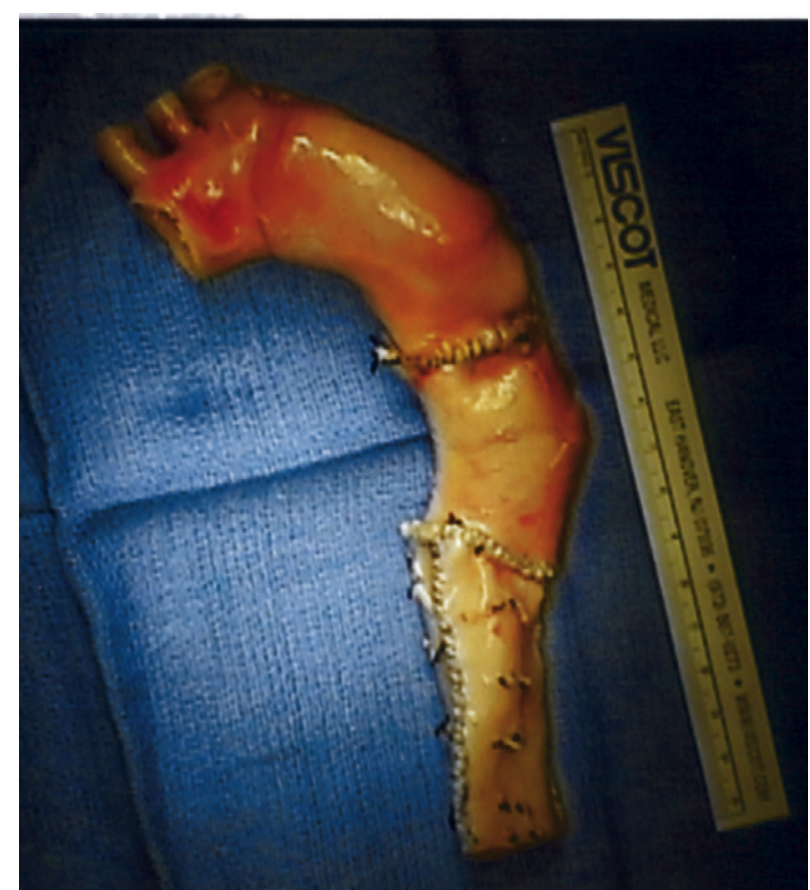

FIGURE 2. Aortic arch and descending thoracic aorta composite graft with 3 segments made from 4 homografts. the proximal homograft allowed the composite graft to mimic the natural shape of the arch. Cutting smaller DTA homograft pieces longitudinally and then sewing them together to form a single element worked well to achieve needed length. Although technically challenging, composite homograft repairs offer a viable solution to these frequently mortal complications.

\section{References}

1. Moulakakis KG, Mylonas SN, Antonopoulos CN, Kakisis JD, Sfyroeras GS, Mantas G, et al. Comparison of treatment strategies for thoracic endograft infection. J Vasc Surg. 2014;60:1061-71.

2. Blasco-Lucas A, Reyes-Juárez JL, Nazarena Pizzi M, Permanyer E, Evangelista A, Galiñanes M. Aortic arch mycotic aneurysm due to Scedosporium apiospermum reconstructed with homografts. Ann Thorac Surg. 2015;99: 2218-20.

3. Kondo T, Hirota M, Kondo S, Hoshino J, Yoshida M, Isomura T. Post-thoracic endovascular aortic repair complicated with mycotic aneurysm rupture, repaired by redo thoracic endovascular aortic repair. Ann Vasc Surg. 2016;33: 228.e1-4.

4. Smeds MR, Duncan AA, Harlander-Locke MP, Lawrence PF, Lyden S, Fatima J, et al. Vascular Low-Frequency Disease Consortium. Treatment and outcomes of aortic endograft infection. J Vasc Surg. 2016;63:332-40.

5. Umminger J, Krueger H, Beckmann E, Kaufeld T, Fleissner F, Haverich A, et al. Management of early graft infections in the ascending aorta and aortic arch: a comparison between graft replacement and graft preservation techniques. Eur $J$ Cardiothorac Surg. May 12, 2016 [Epub ahead of print]. 